\title{
First record of the genus Leonardiella in China, with the description of the Leonardiella pappi sp. nov. from Hong Kong (Acari: Mesostigmata: Trachyuropodidae)
}

\section{Jenő KONTSCHÁN [D}

Plant Protection Institute, Centre for Agricultural Research, ELKH, H-1525 Budapest, P.O. Box 102, Hungary

e-mail: jkontschan@gmail.com

Received: 14 April 2021

Accepted: 4 June 2021

Available online: 31 July 2021

ASBTRACT: Leonardiella pappi sp. nov. is described based on six females and two males collected from soil under Machilus sp., in Tai Po Kau Nature Reserve, in Hong Kong. The new species differs from the other species from the congeners in the shape of dorsal and ventral setae and dorsal and ventral sculptural pattern. A new diagnosis to the genus Leonardiella and a new catalog to all known species are given.

Keywords: Mite, new species, South-East Asia.

Zoobank: http://zoobank.org/B02CF959-16EB-47B3-855A-2223DA11D129

\section{INTRODUCTION}

The family Trachyuropodidae (Acari: Mesostigmata) is one of the well-recognized groups of the suborder Uropodina. Their body is usually large, strongly sclerotized, and covered by depressions and ridges in dorsal and ventral sides. Internal malae on gnathosoma are divided into numerous, apically pilose or smooth branches (like a mustache), characteristic T-shaped setae with a short stem and long cross-bar can be observed on the body of majority of the known species (Kontschán, 2007; Lindquist et al., 2009).

The genus Leonardiella Berlese, 1904 is a very characteristic group within this family by having a triangular or pentagular shape of the idiosoma and the presence of a pair of ventral depression posterior to coxae IV (Kontschán, 2011b). The genus contains thirteen species described from the Holactis and tropical realms (Kontschán, 2011a).

During the last visit of the author to Geneva's Natural History Museum some soil samples from Hong Kong were investigated. One of the samples contained several specimens of a new Leonardiella species described herein as first report of this genus from Hong Kong and from China.

\section{MATERIALS AND METHODS}

The female and male specimens were cleared in lactic acid for a week and later, they were investigated on halfcovered deep slides with a Leica 1000 microscope. Drawings were made with the aid of a drawing tube on a Leica 1000 microscope. All specimens are stored in $75 \%$ ethanol and deposited in the Natural History Museum in Geneva. Abbreviation: $h=$ hypostomal setae. All measurements and the scale bars in the figures are given in micrometres $(\mu \mathrm{m})$.

\section{RESULTS}

Leonardiella Berlese, 1904
Trachyuropoda (Leonardiella) Berlese, 1904: 367.

Diagnosis. Shape of idiosoma triangular or pentagonal. Dorsal shield with lateral decision at level of coxae IV. Dorsal shield with strongly sclerotized straight, undulate or ring-like grooves. One pair of transversal furrows bordered by setae situated posterior to coxae IV on ventral idiosoma. Genital shield of female scuti- or linguliform. Leg I with claws.

Type species: Uropoda canestriniana Berlese, 1891: 4, by original designation.

\section{List of the known Leonardiella species}

Leonardiella athiasae (Hirschmann, 1975)

Trachyuropoda athiasae Hirschmann, 1975: 103.

Occurrence and habitat: Chad, from gallery forest (Hirschmann, 1975).

Leonardiella canestriniana (Berlese, 1891)

Uropoda canestriniana Berlese, 1891: (without page number).

Occurrences and habitat: Italia, French, Great-Britannia, from nests of ants (Wiśniewski and Hirschmann, 1993).

Leonardiella cistulata (Hirschmann, 1975)

Trachyuropoda cistulata Hirschmann, 1975: 103-104.

Occurrence and habitat: Sri Lanka, without information about the habitat (Hirschmann, 1975).

Leonardiella constricta (Banks, 1916)

Trachyuropoda constricta Banks, 1916: 231.

Occurrence and habitat: Australia, together with ants (Wiśniewski and Hirschmann, 1993).

Leonardiella cubana Kontschán, 2011

Leonardiella cubana Kontschán, 2011b: 211-213. 
Occurrence and habitat: Cuba, from leaf litter of a coffee plantation (Kontschán, 2011b).

Leonardiella harteni Kontschán, 2011

Leonardiella harteni Kontschán, 2011a: 29-31.

Occurrence and habitat: United Arab Emirates, from leaf litter of a garden (Kontschán, 2011a).

Leonardiella koreana Kontschán, Park, Yoon and Choi, 2012

Leonardiella koreana Kontschán, Park, Yoon and Choi, 2012: 173-175.

Occurrence and habitat: North-Korea, from soil (Kontschán et al., 2012).

Leonardiella machadoi Kontschán, 2006

Leonardiella machadoi Kontschán, 2006: 4-7.

Occurrence and habitat: Angola, without information about the habitat (Kontschán, 2006).

Leonardiella matsuurai (Hiramatsu, 1980)

Trachyuropoda matsuurai Hiramatsu, 1980: 25.

Occurrence and habitat: Japan, from forest soil (Hiramatsu, 1980).

Leonardiella riccardiana (Leonardi, 1895)

Uropoda riccardiana Leonardi, 1895: 318.

Occurrence and habitat: Austria, Romania, Czech Republic, Slovakia, Italia, Hungary, Iran, from nests of ants (Wiśniewski and Hirschmann, 1993, Arjomandi and Kazemi, 2014).

Leonardiella septentrionalis (Berlese, 1904)

Trachyuropoda (Leonardiella) canestriniana (Berlese, 1891) var. septentrionalis Berlese, 1904: 369.

Occurence and habitat: Russia, from nests of ants (Wiśniewski and Hirschmann, 1993).

Leonardiella similiathiasae (Hiramatsu, 1979)

Trachyuropoda similiathiasae Hiramatsu, 1979: 106.

Occurrence and habitat: Japan, from forest soil (Hiramatsu, 1979).

Leonardiella whitkombi (Hirschmann, 1975)

Trachyuropoda whitkombi Hirschmann, 1975: 103.

Occurrence and habitat: Brazil, from nests of ants (Hirschmann, 1975).

\section{Leonardiella pappi sp. nov.}

Zoobank: http://zoobank.org/02B52A0E-478F-414FAC04-D3AEF6F0609F

(Figures 1-10)

Diagnosis. Dorsal shield with one pair of U-shaped, strongly sclerotized lateral incision at level of coxae IV on dorsal shield, and a strongly sclerotized ring-like groove situated between two lateral incisions. Dorsal shield covered by oval pits but reticular sculptural pattern situated anterior and posterior to ring-like groove. Female genital shield linguliform covered by oval pits. One pair of deep and lateral furrow with smooth and needle-like setae on their margins situated posterior to coxae IV on ventral idiosoma.

Material examined. Holotype. Female. Hong Kong, New Territories, Tai Po Kau Nature Reserve, forest along "Tai Po Kau Trail", soil sample under Machilus sp., 160 m; 14.III.2000; leg. B. Hauser (Berlese extraction in Geneva). Paratypes. Five females and two males, collection data as in holotype.

\section{Description}

Female $(n=6)$.

Description. Length of idiosoma 650-690, width 380-440. Shape pentagonal, posterior margin rounded, colour reddish brown.

Dorsal idiosoma (Fig. 1). Marginal and dorsal shields completely separated. Majority of dorsal setae T-shaped with a short stem and long cross-bar (ca 14-17), some long, wide and marginally pilose setae (ca 23-33 long) placed around lateral incision of dorsal shield. One pair of Ushaped, strongly sclerotized, 71-80 long and 44-52 wide lateral incision situated at level of coxae IV on dorsal shield. A strongly sclerotized, 43-47 long and 78-85 wide ring-like groove situated between two lateral incisions. Dorsal shield covered by oval pits (ca $4-5 \times 3-6$ ), but reticular sculptural pattern situated anterior and posterior to ring-like groove. Two pairs of pores placed posterior to lateral incisions. Marginal shield wide, without sculptural pattern and setation.

Ventral idiosoma (Fig. 2). Sternal shield covered by some oval pits (ca 2-4×2-5) close to apical margin, other parts smooth. Ten pairs of sternal setae T-shaped, their crossbar ca 10-11 long. Seven sternal setae situated close to anterior and lateral margin of genital opening, three pairs between coxae III and IV. One pair of deep and lateral furrow (46-50 long and 110-120 wide) with smooth and needle-like (ca 23-27 long) setae on their margins situated posterior to coxae IV. Surface of ventral shield smooth. First pair of ventral setae wide and pilose (ca 27-30 long), other ventral setae T-shaped, their crossbar ca 20-23 long. Setae around anal opening similar in shape to ventral setae, but shorter (their crossbar ca 10-13).

One pair of large $(85-90 \times 80-90)$ rounded holes situated at caudal edges on ventral idiosoma, surface of holes covered by reticulate sculptural pattern. Anal opening small, ca 15-18 long and ca 4-5 wide. One pair of large pores situated anterior to anal opening and one pair of small pores lateral to anal opening. Peritremes (Fig. 3) without poststigmatid part and with a long and hairpin-like prestigmatid part. Stigmata situated between coxae II and III. Genital shield wide, linguliform (206-210 long and 105109 wide), without apical process. Surface of genital shield covered by oval pits (ca 4-6×3-5). 


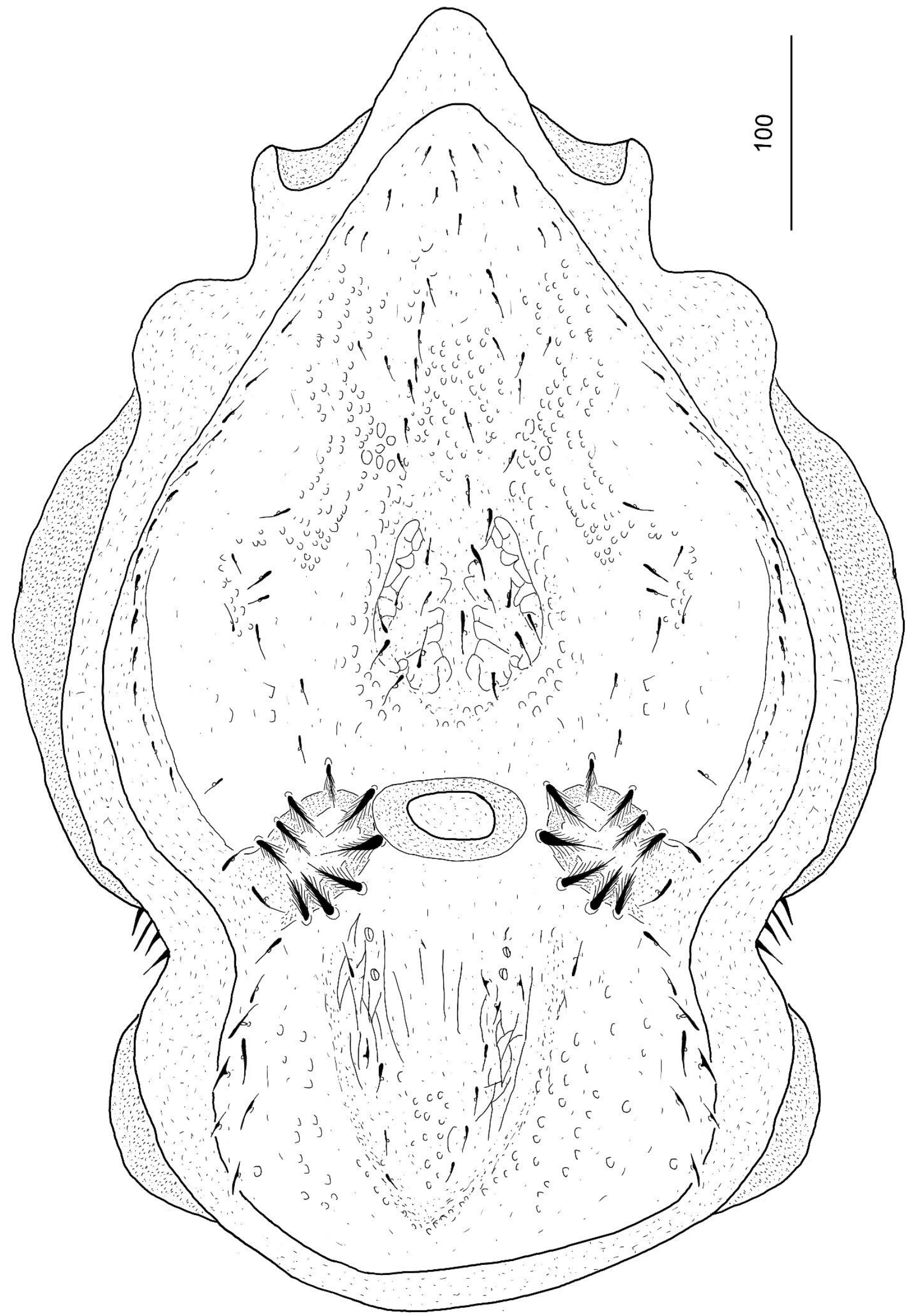

Figure 1. Dorsal view of Leonardiella pappi sp. nov. female, holotype. 


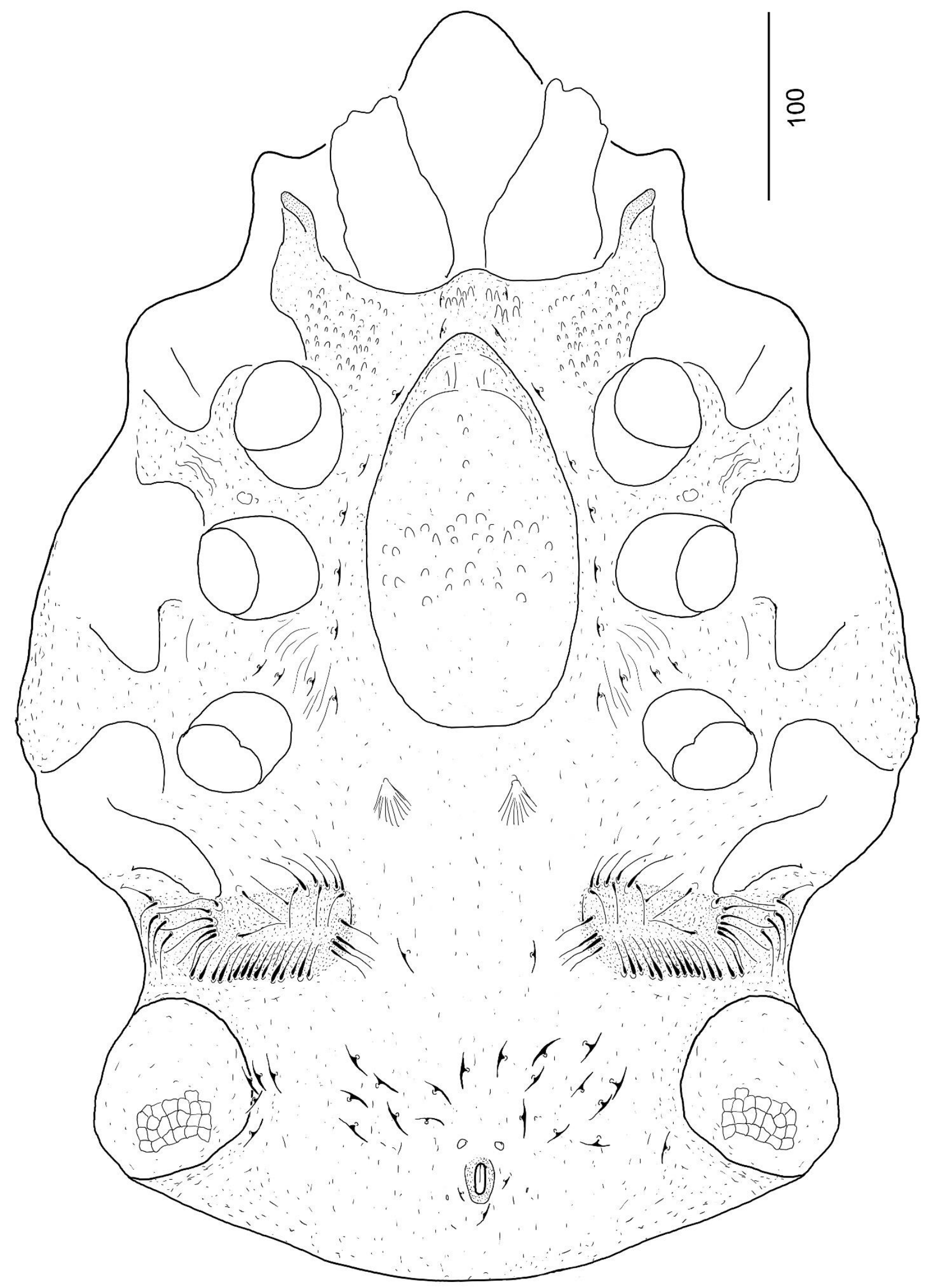

Figure 2. Ventral view of Leonardiella pappi sp. nov. female, holotype. 


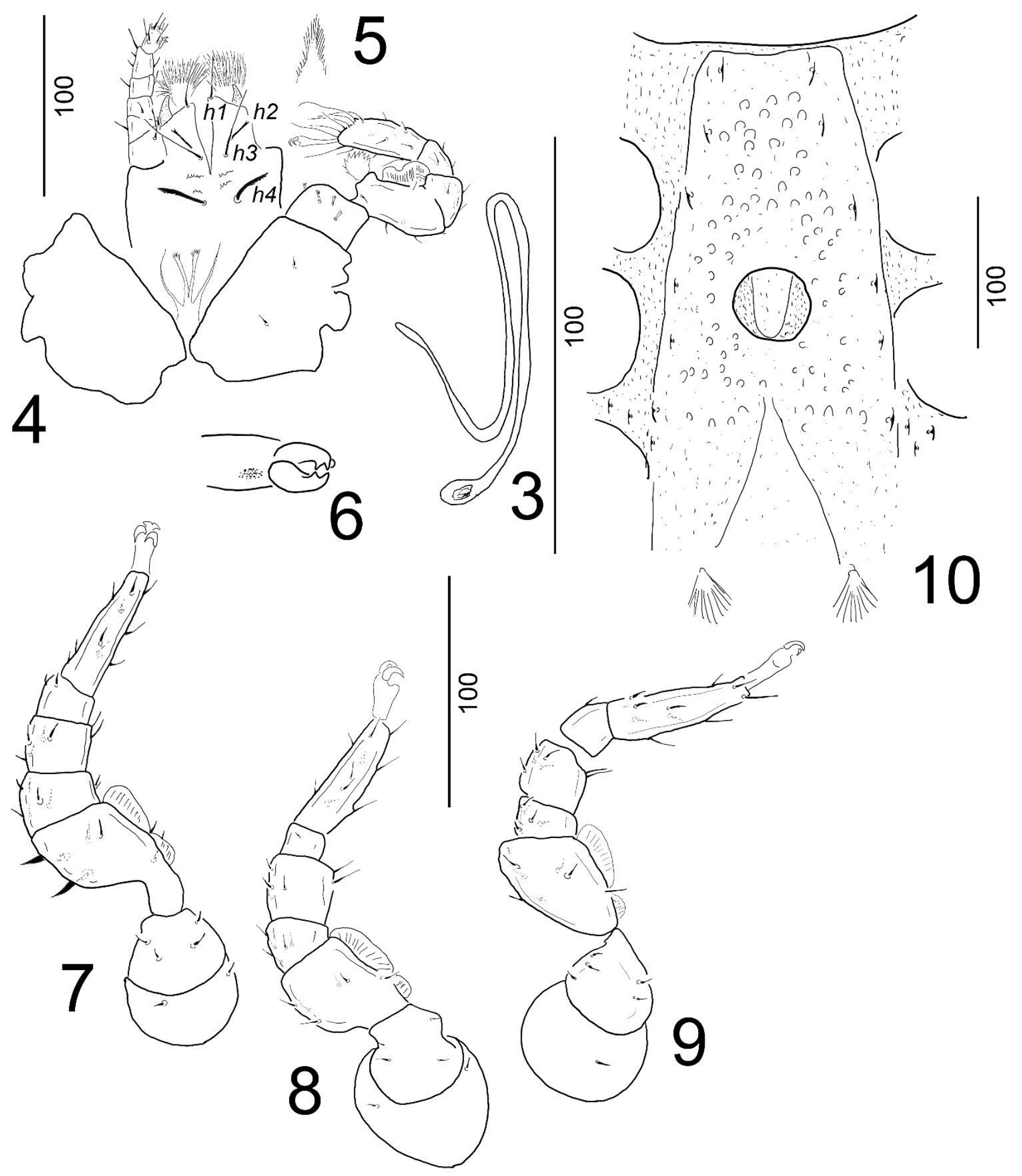

Figures 3-10. Leonardiella pappi sp. nov. female, holotype. 3. Peritreme. 4. Gnathosoma, tritosternum, palp and leg I in ventral view. 5. Apical part of epistome. 6. Lateral view of chelicera. 7. Leg II in ventral view. 8. Leg III in ventral view. 9. Leg IV in ventral view. 10. Intercoxal area of male paratype.

Pedofossae deep, their surface smooth, separate furrows for tarsi IV present. Base of tritosternum narrow, vaselike, tritosternal laciniae divided into two smooth lateral and two apically pilose central branches (Fig. 4).

Gnathosoma (Fig. 4). Corniculi horn-like, internal malae longer than corniculi and divided into numerous smooth branches. Hypostomal setae $h 1$ situated on apical margin of gnathosoma, ca 19-23 long, smooth and needle-like, h2 apically bifurcated and ca 15-17 long, $h 3$ very long (ca 3740) smooth and needle-like, $h 4$ ca 17-18 long and marginally pilose. Two rows of denticles between $h 3$ and $h 4$ present. Palp setae smooth and needle-like. Episome apically pilose (Fig. 5). Fixed digit of chelicerae as long as movable digit with one-one central tooth on both digits. Internal sclerotized nodes present (Fig. 6). 
Legs (Figs 7-9). Majority of setae on legs smooth and needle-like, except four pilose setae trochanter of leg I and one large serrate ventral seta on femur of leg I. Claws on first leg smaller than on other legs. All femora bearing flap-like ventral processes. Leg I 230-240, leg II 215-220, leg III 205-210, leg IV 230-240.

Male $(n=2)$.

Length of idiosoma 650-690, width 380-440.

Dorsal idiosoma. Ornamentation and chaetotaxy of dorsal shield as for female.

Ventral idiosoma (Fig. 10). Sternal shield with nine pairs of T-shaped setae, their crossbar ca 12-15 long. Sternal shield covered by oval pits (ca $4-5 \times 4-5$ ). Genital shield oval (45-47×50-52) and situated between coxae II. Other characters as in female.

Larva and nymphs. Unknown.

Etymology. The new species is dedicated to the excellent Hungarian fly specialist and zootaxonomist, Prof. Dr. László Papp (1946-2021), who passed away this year.

Remark. Till today only four species are reported from East- and South-East Asia, namely Leonardiella cistulata, L. koreana, L. matsuurai and L. similiathiasae.. The new species differs from these four ones in the presence of the strongly sclerotized ring-like dorsal groove, which is absent in these four species. One pair of U-shaped, strongly sclerotized lateral incision at the level of coxae IV on dorsal shield are visible only on the new species and on the $L$. similiathiasae, but the reticulate sculptural pattern on dorsal shield absent on L. similiathiasae (this character is visible on the new species) and setae around horizontal furrow on ventral idiosoma are pilose on L. similiathiasae, contrary they are smooth on the new species.

\section{Statement of ethics approval}

Not applicable.

\section{Funding}

There is no fund for the present study.

\section{Conflict of interest}

No potential conflict of interest was reported by the author.

\section{Acknowledgement}

I am very grateful to Dr. Peter Schwendinger (Natural History Museum of Geneva) for his kind hospitality during my stay in Geneva.

\section{REFERENCES}

Arjomandi, E. and Kazemi, S. 2014. Edaphic mesostigmatic mites (Acari: Mesostigmata) fauna in parks and landscapes of Kerman City. The Third Insect Pest Man- agement Conference, Kerman, Shahid Bahonar University of Kerman, Kerman, Iran, 243-251.

Banks, N. 1916. Acarians from Australian and Tasmanian ants and ant nests. Transactions, Proceedings and Report, Royal Society of South Australia, 40: 224-240.

Berlese, A. 1891. Acari, Myriopoda et Scorpiones hucusque in Italia reperta, 58, 18 text pages + plates 110. Reprint by Junk, The Hague, 1979. [In Italian]

Berlese, A. 1904. Illustrazione iconografica degli Acari mirmecofili. Redia, 1: 299-474. [In Italian]

Hiramatsu, N. 1979. Gangsystematik der Parasitiformes. Teil 332. Teilgang, Stadium von 2 neuen Trachyuropoda-Arten aus Japan (Trachyuropodini, Oplitinae). Acarologie, Schriftenreihe für Vergleichende Milbenkunde, 25: 105-107. [In German]

Hiramatsu, N. 1980. Gangsystematik der Parasitiformes. Teil 359. Stadium einer neuen Trachyuropoda-Art der Canestriniana-Gruppe aus Japan (Trachyuropodini, Oplitinae). Acarologie, Schriftenreihe für Vergleichende Milbenkunde, 27: 25-26. [In German]

Hirschmann, W. 1975. Gangsystematik der Parasitiformes. Teil 214. Stadien von 8 neuen TrachyuropodaArten (Trachyuropodini, Oplitinae). Acarologie, Schriftenreihe für Vergleichende Milbenkunde, 21: 101-105. [In German]

Kontschán, J. 2006. Uropodina (Acari: Mesostigmata) species from Angola. Acta Zoologica Academiae Scientiarum Hungaricae, 52 (1): 1-20.

Kontschán, J. 2007. Trachyuropodid mites of the Carpathian Basin (Acari: Uropodina: Trachyuropodidae). Opuscula Zoologica Budapest, 36: 43-56.

Kontschán, J. 2011a. Order Mesostigmata, family Trachyuropodidae. In: Arthropod fauna of the UAE Volume 4. van Harten, A. (Ed.). Dar Al Ummah Printing, Publishing and Advertising, Abu Dhabi, UAE, 29-32.

Kontschán, J. 2011b. Six new species of family Trachyuropodidae from the Neotropical region (Acari: Mesostigmata: Uropodina). Studies on Neotropical Fauna and Environment, 46 (3): 211-223. doi: 10.1080/01650521.2011.618034

Kontschán, J., Park, S.J., Yoon, T.J. and Choi, W.Y. 2012. New Uropodina records and species from the Korean Peninsula (Acari: Mesostigmata). Opuscula Zoologica Budapest, 43 (2): 169-177.

Leonardi, G. 1895. Intorno ad alcune nuove specie di Acari italiani ecc. Atti della Societá Veneto Trentina di Scienze Naturali, 2: 318. [In Italian]

Lindquist, E.E., Krantz, G.W. and Walter, D.E. 2009 Order Mesostigmata. In: A manual of acarology. 3rd Edition. Krantz, G.W. and Walter, D.E. (Eds). Texas University Press, Lubbock, Texas, USA, 124-232. 
Wiśniewski, J. and Hirschmann, W. 1993. Gangsystematik der Parasitiformes. Teil 548. Katalog der Ganggattungen, Untergattungen, Gruppen und Arten der Uropodiden der Erde (Taxonomie, Literatur, Grösse, Verbrei- tung, Vorkommen). Acarologie. Schriftenreihe für Vergleichende Milbenkunde, 40: 1-220. [In German]

Edited by: Raşit Urhan

Reviewed by: Two anonymous referees

Citation: Kontschán, J. 2021. First record of the genus Leonardiella in China, with the description of the Leonardiella pappi sp. nov. from Hong Kong (Acari: Mesostigmata: Trachyuropodidae). Acarological Studies, 3 (2): 82-88. 